\title{
TITLE:
}

\section{Tensile and Tensile-Mode Fatigue Testing of Microscale Specimens in Constant Humidity Environment}

\author{
$\operatorname{AUTHOR}(\mathrm{S})$ : \\ Tsuchiya, T.; Yamaji, Y.; Sugano, K.; Tabata, O.
}

\section{CITATION:}

Tsuchiya, T.... [et al]. Tensile and Tensile-Mode Fatigue Testing of Microscale Specimens in Constant Humidity Environment. Experimental Mechanics 2010, 50(4): 509-516

\section{ISSUE DATE:}

2010-04

URL:

http://hdl.handle.net/2433/120793

\section{RIGHT:}

The original publication is available at www.springerlink.com; This is not the published version. Please cite only the published version.; この 論文は出版社版でありません。引用の際には出版社版をご確認ご利用 ください。 


\section{TENSILE AND TENSILE-MODE FATIGUE TESTING OF MICROSCALE SPECIMENS IN CONSTANT HUMIDITY ENVIRONMENT}

TOSHIYUKI TSUCHIYA, YUSUKE YAMAJI, KOJI SUGANO AND OSAMU TABATA

Department of Micro Engineering, Kyoto University

Yoshida-Honmachi, Sakyo-ku, Kyoto 606-8501, Japan

A tensile and tensile-mode-fatigue tester has been developed for testing microscale specimens in high humidity environments in order to investigate the fracture mechanisms of microelectromechanical materials. A humidity control system was installed on a tensile-mode fatigue tester equipped with an electrostatic force grip. A specimen and a griping device were inserted into a small chamber and the humidity was controlled by air flow from a temperature and humidity chamber. The humidity stability was within $\pm 2 \% \mathrm{RH}$ for humidities in the range $25-90 \% \mathrm{RH}$ for eight hours of testing. Fatigue tests were performed on single-crystal silicon (SCS) specimens in constant humidity environments and laboratory air for up to $10^{6}$ cycles. The gauge length, width, and thickness of the SCS specimens were 100 or $500 \mu \mathrm{m}, 13.0 \mu \mathrm{m}$, and $3.3 \mu \mathrm{m}$, respectively. The average tensile strength was $3.68 \mathrm{GPa}$ in laboratory air; this value decreased in high humidity environments. Fatigue failure was observed during cyclic loading at stresses lower than the average strength. A reduction in the fatigue strength was observed at high relative humidities. Different fracture origins and fracture behaviors were observed in tensile tests and fatigue tests, which indicates that the water vapor in air affects the fatigue properties of SCS specimens. 


\section{Introduction}

The reliability of microelectromechanical systems (MEMS) is a matter of great concern since they are currently used in a wide variety of devices, including automotive, industrial, and consumer devices. The compactness of MEMS permits them to be used in portable devices, which makes their reliability even more critical. In contrast with microelectronics devices, MEMS need to be mechanically reliable. Therefore, the mechanical reliability of the materials used in MEMS must be determined to predict their lifetimes. However, single-crystal silicon (SCS), which is one of the most popular structural materials in MEMS, is brittle. Its fracture and fatigue mechanisms have yet to be determined, despite extensive fatigue testing having been conducted $[1,2,3,4,5,6,7]$. One reason why it has not been possible to determine the fracture and fatigue mechanisms from the testing results might be the difficulty in performing stress analysis due to the loading methods employed in the testing. The specimens in these tests were subjected to bending stress because it is possible to apply high stress at high frequencies using resonant vibration. On the other hand, it is important to consider the stress concentration or singularity around a point of maximum stress generated by an intentionally introduced notch or by a non-ideal boundary condition. Testing under a uniaxial tensile stress is a basic material testing method and is being applied to MEMS materials. Many useful results, such as the effect of sample size on the strength of polysilicon [8], the effect of humidity on the strength of silicon dioxide [9], and plastic deformation of silicon at a relatively low temperature $[10,11]$, have been observed using uniaxial tensile testing. Recently, tensile-mode fatigue tests using a tensile tester have been conducted $[12,13]$.

To determine the fatigue failure mechanisms of SCS, it is important to consider 
environment control when conducting fatigue testing. Previous test results when specimens were subjected to a bending stress revealed that fatigue fracture of both SCS $[2,3]$ and polysilicon [14] was affected by humidity. Since the fatigue properties are severely degraded in a high humidity environment [3], it is important to conduct fatigue testing of silicon in a high humidity environment when investigating its fatigue failure mechanisms. In the case of tensile testing, it is very challenging to achieve control of the testing environment because high humidities can be harmful to test equipment, such as force sensors and actuators. This accounts for why no such testing methods have been reported.

In this study, environment-controlled tensile-mode fatigue testing was performed using a newly developed fatigue tester equipped with an electrostatic grip [8] for specimen chucking. The grip is suitable for testing environmental control because it is simple to install and it can be controlled remotely. Using this tester, tensile-mode fatigue testing of SCS was performed and the fatigue strength was measured as a function of the humidity to investigate fatigue fracture mechanisms.

\section{Tensile-mode fatigue tester}

\subsection{Electrostatic grip}

For the electrostatic grip system, a specimen is a cantilever beam structure fabricated on a substrate using surface micromachining. The fixed end is supported by the substrate and the free end is a large paddle that is fixed using the grip. The grip is a strip made from silicon wafer covered with a silicon nitride insulating film. A voltage of up to 200 $\mathrm{V}$ is applied between a conductive thin-film specimen and the grip. The friction force 
generated by the normal force on the contacted surfaces between the grip and specimen holds the specimen in place during tensile testing. The main features of the system are follows:

- Easy handling of and minimal damage to fragile thin-film specimens, because it is not necessary to touch the specimens directly during either testing or preparation and cleaning.

- The grip force can be controlled by the applied voltage. This permits remote testing to be performed, such as testing in a vacuum chamber, environmental chamber, and using analysis equipment. Simultaneous testing is also possible with this system.

In this experiment, the insulating silicon nitride film was $0.2 \mu \mathrm{m}$ thick. The dimensions of the griping area of the silicon strip were $1 \mathrm{~mm} \times 10 \mathrm{~mm}$. The minimum voltage to hold the specimen was estimated using the following equation:

$$
F_{\text {friction }}=\mu F_{\text {electrostatic }}=\frac{\mu \varepsilon_{\mathrm{r}} \varepsilon_{0} Q V^{2}}{2 d^{2}}
$$

where $\varepsilon_{\mathrm{r}}$ is the relative permittivity of silicon nitride, $\varepsilon_{0}$ is the dielectric constant, $Q$ is the contact area, $V$ is the applied voltage, $d$ is the thickness of the silicon nitride specimen, and $\mu$ is the friction coefficient between the specimen and the grip surface. The grip force, which is equal to the friction force $F_{\text {friction, }}$, must be larger than the specimen fracture force, which is given by

$$
F_{\text {friction }}>\sigma_{\mathrm{f}} w t
$$

where $\sigma_{\mathrm{f}}$ is the fracture stress, $w$ is the width, and $t$ is the thickness of the specimen. The following parameters were used in this study: $\varepsilon_{\mathrm{r}}=8, Q=0.6 \times 1.05$ 
$\mathrm{mm}^{2}, d=0.2 \mu \mathrm{m}, w=20 \mu \mathrm{m}$, and $t=2 \mu \mathrm{m}$. The reported fracture stress $\sigma_{\mathrm{f}}$ of SCS ranges from 2 to $6 \mathrm{GPa}$. To estimate the voltage applied to the grip system, we need to know the friction coefficient of the contact surface between silicon and silicon nitride. Assuming that the friction coefficient is 0.3 , which is a commonly used value for macroscale objects, the required voltage is calculated to be $38 \mathrm{~V}$. The electrical breakdown strength of low-pressure chemical vapor deposited silicon nitride film is approximately $1.1 \mathrm{MV} / \mathrm{cm}$. Up to $200 \mathrm{~V}$ can be applied to the grip system, so electrostatic grip is feasible under the present conditions.

Slipping at the grip during cyclic loading could be problematic because the holding force of the grip system is less than that of a mechanical grip. However, since we did not observe a change in the stage displacement offset or amplitude during fatigue tests, we conclude that the grip is strong enough for fatigue loading.

\subsection{Testing equipment}

Figure 1 shows a schematic diagram of the tensile-mode fatigue tester. In order to realize a high loading frequency of up to $100 \mathrm{~Hz}$, we were careful to select a load cell and a loading actuator that have resonant frequencies much higher than $100 \mathrm{~Hz}$. For example, a load cell with a small force range usually has a low resonant frequency because its stiffness is low to enable it to generate a large strain for a small force. Instead, we used a 5-N range load cell (Kyowa Electric Instruments, LTS-500GA) with a resonant frequency of $1 \mathrm{kHz}$. A piezoelectric stage (PI-Polytec, P-780.20) was used to apply the tensile load; it can generate an $80-\mu \mathrm{m}$ displacement at $100 \mathrm{~Hz}$.

The specifications of the developed tester are listed in Table 1. The maximum test frequency is $100 \mathrm{~Hz}$; by contrast, our previously developed tensile tester could be 
operated only up to $1 \mathrm{~Hz}$. The stage displacement control signal is generated by a function generator (NF Corporation, DF1905) controlled by a personal computer (PC) via a USB interface. The actuation signal is supplied to a piezoelectric stage controller (PI-Polytec, E-503) to actuate the piezoelectric stage. The piezoelectric stage has a linear variable differential transformer (LVDT) displacement sensor and its position signal is fed back to the controller to compensate for the nonlinear response and hysteresis of the piezoelectric actuator. The load cell is connected to a preamplifier (Kyowa Electric Instruments, WGA-710B). The output of the preamplifier is filtered and amplified by a signal amplifier (Kyowa Electric Instruments, DA-510B). The gain of the amplifier is 20 and the cut-off frequency of the low-pass filter is $1 \mathrm{kHz}$. The force and stage displacement signal are acquired using an $\mathrm{A} / \mathrm{D}$ converter interface board installed in the PC. The resonant frequencies of the piezoelectric stage and the load cell are $1 \mathrm{kHz}$ and $1.1 \mathrm{kHz}$, respectively, which are sufficiently high for testing at $100 \mathrm{~Hz}$. Photographs of the tester are shown in Figure 2. An optical microscope (Nikon, ME600) equipped with a CCD camera (Nikon, HC-300Zi) was used for observing the test procedure. The specimen chip was placed on a two-axis manual stage (Sigma Koki, TDS-601C) used for horizontal alignment of the specimen and grip. The vertical gap between the specimen and the grip was controlled by moving the specimen stage with a micrometer actuator (Sigma Koki, SOM-B15E).

\subsection{Tensile force loading and measurement}

The piezoelectric stage displacement was monitored with a built-in LVDT displacement sensor. The tensile force was measured using the load cell. Since the maximum force to be measured during tensile testing was about $250 \mathrm{mN}$, which is one twentieth of the 
rated measurement capacity of $5 \mathrm{~N}$, the output of the load cell was amplified. The sensitivity of the force output was $0.024 \mathrm{~V} / \mathrm{N}$. The root-mean-square voltage of the noise of the force output was $23 \mathrm{mV}$, which corresponds to a force of $0.56 \mathrm{mN}$. This noise level of the force output is sufficiently small for this test because it is about $0.2 \%$ of the estimated average tensile strength of the silicon specimens. No drift in the force output was observed.

\subsection{Humidity control}

In this study, the humidity of the test environment needs to be controlled and monitored; this is especially important for testing in high humidity environments. However, the high humidity may damage the test instruments making it difficult to put the whole test system into a high humidity environment. Thus, to control the testing environment, a small chamber was installed so that the specimen and electrostatic grip were separated from the load cell and stages. The humidity in the chamber was controlled by circulating constant humidity air from a temperature and humidity chamber (Espec, SH-221). These two chambers were connected by two heat insulating tubes and an electric fan was inserted in the middle of the tube line to generate a circulating flow. The temperature and humidity in the small chamber were monitored using a thermohygrometer (Hioki, 3641). The sensor was placed in the small chamber close to the specimens. The net flow rate of the circulating air was measured as a function of the voltage, as shown in Figure 3. At $12 \mathrm{~V}$, the flow rate was $2400 \mathrm{ml} / \mathrm{min}$ and the flow velocity was $64 \mathrm{~mm} / \mathrm{s}$, which are relatively large compared to the small volume of the chamber. Therefore, we assume that the humidity in the small chamber will be constant even although it was not completely sealed since there was a connecting rod between the grip and the load cell 
located outside the chamber.

\subsubsection{Humidity stability}

The humidity stability in the test chamber was measured. The temperature and humidity in the chamber were $25{ }^{\circ} \mathrm{C}$ and $25 \% \mathrm{RH}$ respectively, while those in the laboratory were $21{ }^{\circ} \mathrm{C}$ and $50 \% \mathrm{RH}$, respectively. Figure 4 shows the temperature and humidity in the chamber as a function of the voltage applied to the electric fan. The temperature decreased slightly as the flow rate increased. This may be due to laboratory air being sucked into the chamber. Therefore, we chose a fan voltage of $9 \mathrm{~V}$ to reduce the intake of laboratory air.

The test system can control the relative humidity in the range from $20 \%$ to $100 \%$ at room temperature. The temperature and humidity in the chamber during a fatigue test are shown in Figure 5. The temperature and humidity variations were within $\pm 1{ }^{\circ} \mathrm{C}$ and $\pm 2 \% \mathrm{RH}$, respectively. These variations were caused by fluctuations in the temperature of the air-conditioned laboratory. In order to reduce these variations, the chamber should be installed with a temperature control system.

The load cell output noise was measured because the circulating air flow is high compared to the chamber size and it may cause noise and drift in the force output. Figure 6 shows the peak and valley values of the tensile stress and piezoelectric stage displacement during fatigue testing of an SCS specimen tested at $26{ }^{\circ} \mathrm{C}, 87 \% \mathrm{RH}$. The gauge length of the SCS specimen was $500 \mu \mathrm{m}$. The peak stress was $2.75 \mathrm{GPa}$ and the stress ratio was 0.134 . Figure 7 shows the waveforms of the stress and stage displacement for the same specimen. Both plots show that the air flow has no significant effect on the force measurement. In addition, the peak and valley values were stable 
sinusoidal waveforms with no fluctuations or disturbance. Fracture occurred at the maximum tensile stress and no fluctuation in the stress was observed, which indicates that the developed fatigue testing system operated properly. Thus, it can be concluded that the system is able to perform tensile-mode fatigue testing in a constant humidity environment.

\section{Experimental Procedure}

\subsection{Specimens}

SCS specimens were fabricated from a silicon-on-insulator (SOI) wafer. The nominal thickness of the device layer was $2 \mu \mathrm{m}$. Two types of the specimens were used: they had lengths of 120 and $600 \mu \mathrm{m}$ for the parallel section, as shown in Figure 8. Each specimen has two gauge marks on the parallel section; the gauge length was 100 or $500 \mu \mathrm{m}$. The cross-sectional dimensions of all the specimens were measured after failure by scanning electron microscopy (SEM). This was done because the thickness variations of the device layer of raw SOI wafers are large and the undercut produced by dry etching of the device layer caused large variations in the specimen width. The average thickness was $3.3 \mu \mathrm{m}$ and the cross-sectional area was $40 \mu \mathrm{m}^{2}$.

\subsection{Quasi-static tensile test}

Quasi-static tensile tests were performed to determine the fatigue test conditions. A tensile load was applied by displacing the piezoelectric stage at a rate of $0.5 \mu \mathrm{m} / \mathrm{sec}$.

\subsection{Fatigue test}

Fatigue tests were conducted for three different humidity conditions. The temperature and humidity during the fatigue tests are summarized in Table 2. Tests in high and low 
humidity conditions were performed using the humidity control system. For tests performed in laboratory air, the chamber cover was removed to expose the specimens to laboratory air. The maximum stress of the sinusoidal cyclic stress was set between 50 and $100 \%$ of the average tensile strength measured in the quasi-static test in laboratory air. The test frequency was $40 \mathrm{~Hz}$, the stress ratio was $0.1-0.2$, and the maximum number of cycles was $10^{6}$. If the number of cycles reached $10^{6}$, the maximum stress was increased by $10 \%$ of the average tensile strength and another fatigue test was performed up to $10^{6}$ cycles. This procedure was repeated until specimen fracture occurred.

The peak stress was controlled by setting the stage displacement amplitude. The stress amplitude was sufficiently stable that feedback control was not performed. During the fatigue test, the sampling frequency of the A/D converter was $4 \mathrm{kHz}$. The $\mathrm{A} / \mathrm{D}$ converter board has a ring buffer memory and the sampling was stopped when fracture was detected. The stage movement was stopped after a short time after fracture had occurred because of the checking interval of the fracture detection system.

\section{Results and discussion}

\subsection{Tensile strength}

In quasi-static tensile testing, the specimens exhibited brittle fractures and the tensile force-stage displacement curve showed no yield point. The fractures of SCS were predominately due to defects in the specimens. Figure 9 shows the measured tensile strength in laboratory air against the gauge length. The average tensile strength of eight specimens in laboratory air was $3.68 \mathrm{GPa}$. There were no obvious differences in the strengths of the five longer specimens and those of the three shorter specimens. 
However, the deviation in the strengths of the longer specimens was much smaller than that of the shorter specimens. This may be due to the size effect, but it is difficult to confirm this due to the limited number of tested specimens having large deviations in measured strength.

In addition, the two shorter (100 $\mu \mathrm{m}$ in gauge length) specimens were tensile tested in a high humidity environment. The measured strength was lower than the average strength in laboratory air.

\subsection{Fatigue properties}

The number of fatigue tested specimens was 11, 11, and, 13 in low humidity, laboratory air, and high humidity, respectively. All the results are plotted in Figure 10. Specimens that fractured during initial loading are plotted on the y-axis. The points at $10^{6}$ cycles with arrows indicate specimens that did not fracture at the stress level. These six points are the results from two specimens. Neither specimen fractured during three $10^{6}$ cycles; both of them fractured during initial loading prior to the fourth cycle of fatigue testing. Most specimens fractured during initial loading or fatigue fractured at a stress less than the average tensile strength in laboratory air. These results clearly indicate that the strengths of the SCS specimens decreased with cyclic tensile stress loading. As shown in this quasi-static tensile test and as described in previous reports on fracture testing of SCS, a fracture may be initiated from a crack on the surface. Crack formation and growth may be enhanced by cyclic stress loading.

In a high humidity environment, all the specimens fractured during initial loading or during the first $10^{6}$ cycles of the fatigue test, although the peak stress was lower than that for other test conditions. In a low humidity environment and in laboratory air, the 
data points are distributed in the same region, but there were two specimens tested in the low humidity environment that did not fracture during $10^{6}$ cycles loading at similar peak stresses. This demonstrates that the humidity affects the fatigue properties of SCS.

\subsection{Fracture surfaces}

Fracture surfaces of the tensile-tested and fatigue-tested specimens were observed by field-emission scanning electron microscopy (FE-SEM). A typical fracture surface is shown in Figure 11. The fracture of the tensile-tested specimen was initiated from the lower corner (Figure 11a). By contrast, some fatigue-tested specimens (see Figure 11b) fractured at the gauge mark that was fabricated for the elongation measurement. The other fatigue-tested specimens fractured from the corner in the same way as the tensile-tested specimens. The gauge mark was a sputtered TiW thin film. It is thin enough that its effect can be neglected during the test. However, a step on the silicon surface was formed due to over-etching at the gauge mark pattern, and fracture initiated from this step.

We did not observe any defect or crack near fracture origins in the FE-SEM observations. The critical crack size calculated using Griffith's theory was around $20 \mathrm{~nm}$, which is much smaller than the resolution of the FE-SEM images. This makes it difficult to observe not only the crack but also its growth.

\subsection{Discussion}

Tensile-tensile mode fatigue testing of SCS in high humidity environments revealed two new findings from those obtained by previously reported fatigue testing. First, the tests were conducted using uniaxial tensile testing and a positive stress ratio, which indicates 
that no compressive stress was applied during the test. Kahns et al. deduced that compressive stress induces mechanical damage in silicon and propagates cracks, which results in fatigue fracture [15]. Since no compressive stress was applied to our specimens, mechanical damage was not the cause of our test results. Muhlstein et al. proposed a "reaction layer fatigue model" for silicon fatigue failure and suggested that the susceptibility of silicon-based oxides to stress corrosion cracking is responsible for the fatigue behavior of SCS [5]. Our results may support their observations.

Secondly, we found the humidity affects the tensile strength, something that has not been observed in previous studies. In a previous study, we observed the effect of the environment on the strength of polysilicon films by comparing their strengths in air and in a vacuum [16]. In addition, the effect of the strain rate on the bending strength of SCS structure has been observed [17]. On the other hand, Bagdahn et al. reported that the frequency has no effect on the fatigue properties of polysilicon in tensile and tensile-mode fatigue testing [18], which does not agree with our results. However, their results can be plotted using a straight line in a stress-time plot with acceptable accuracy, since the measured parameters have large deviations. We believe that humidity causes time-dependent strength degradation of silicon structures, which is similar to the static fatigue of glass materials. The degradation process is also related to the surface oxide layer.

The way in which humidity affects strength and fatigue behavior has not yet determined. When subcritical crack formation and growth occurs in the surface oxide layer, the crack cannot grow to its critical size within oxide layer. To cause fracture, there must be a contribution from the silicon structure. Surface roughness of dry-etched silicon can function as a notch on the surface and generate stress concentration at the notch tip. This 
enhances local stress of oxide cracks around the notch tip and may cause fracture from the oxide crack. Another possibility is oxide thickening through existing cracks on the oxide surface, as in the "reaction layer fatigue" of polysilicon [14]. In addition, crack growth into silicon is another possible mechanism. In this case, the surface of the crack in silicon must oxidize, which could explain the effect of humidity on fracture and fatigue properties.

It is possible to limit the effect of humidity on fatigue properties only to reducing the tensile strength. Since the locations of the crack origin are different in tensile testing and fatigue testing, humidity may affect on crack initiation or crack growth during cyclic tensile-tensile loadings. However, the gauge mark effect on fatigue fracture was unexpected and it complicates the investigation of fatigue mechanisms. To overcome this problem, we intend to test specimens without gauge marks that are not used in the developed test system.

\section{Conclusion}

We have developed a new tensile-mode fatigue tester that uses an electrostatic gripping system and that can control the humidity of test environment. Using this tester, the tensile strength and fatigue lifetime of SCS thin films were measured in laboratory air and in a humidity-controlled environment. The peak stress of cyclic loading ranged from 1.6 to $3.7 \mathrm{GPa}$ and the stress ratio ranged from 0.1 to 0.2 . Fatigue fracture was observed and the lifetimes ranged from 1 to $10^{6}$. A reduction in the fatigue strength was observed at high relative humidities. Different fracture origins and fracture behaviors were observed in tensile tests and fatigue tests, which indicates that the water vapor in air affects the fatigue properties of SCS films. These results demonstrate that the 
developed tensile-mode fatigue tester is a useful tool for evaluating the reliability of microscale materials.

\section{Acknowledgments}

Part of this work was supported by the Ministry of Education, Science, Sports and Culture, Grant-in-Aid for Young Researchers, 19676002. 


\section{Tables and Figures Captions}

Table 1: Specifications of fatigue tester

Table 2: Measured temperature and humidity during a fatigue test.

Figure 1: Set-up of the tensile-mode fatigue tester using electrostatic grip system.

Figure 2: Photographs of the tensile fatigue tester. (a) closeup of the testing space (b) closeup of the electrostatic grip system

Figure 3: Relationship between the voltage applied to the electric fan and the flow rate

Figure 4: Temperature and humidity variation in the testing space.

Figure 5: Temperature and humidity variation during a fatigue test.

Figure 6: Peak and valley values of tensile stress and piezoelectric stage displacement in each cycle of fatigue testing.

Figure 7: Tensile stress and piezoelectric stage displacement of SCS specimens at fatigue fracture. The piezoelectric stage movement was terminated after fracture was detected by tensile stress monitoring.

Figure 8: SCS specimens. a) gauge length: $100 \mu \mathrm{m}$, b) gauge length: $500 \mu \mathrm{m}$. 
Figure 9: Measured tensile strength in the laboratory air (lab air) and in high humidity.

Figure 10: S-N plot of SCS specimen for various humidity conditions. The points on the $\mathrm{Y}$ axis indicate specimens that fractured during initial loading. The points at $10^{6}$ cycles with arrows indicate they did not fracture during the $10^{6}$ cycle loading. The points with arrows indicate the results from two samples. The notation "a2" means the second $10^{6}$-cycle fatigue test for specimen " $a$ ".

Figure 11: Fracture surfaces of the specimens. (a) Specimen for quasi-static tensile test. Tensile strength is $3.57 \mathrm{GPa}$. (b) Specimen for tensile-mode fatigue test. Cycles to fracture is $2.72 \times 10^{5}$ cycles. Maximum stress is $2.93 \mathrm{GPa}$ and stress ratio is 0.15 . This specimen was tested in $60 \% \mathrm{RH}$. The arrows indicate the fracture origin. 


\section{References}

1 Mutoh M, Iyoda M, Fujita et al (1990) Development of integrated semiconductor-type acceleration. Proc. of IEEE Workshop on Electronic Applications in Transportation: $35-38$

2 Connally, JA Brown SB (1992) Slow Crack Growth in Single-Crystal Silicon. Science 256:1537-9

3 Tsuchiya T, Inoue A, Sakata J, Hashimoto M, Yokoyama A, Sugimoto M (1998) Fatigue Test of Single Crystal Silicon Resonator. Tech. Dig. 16th Sensor Symp. (Kawasaki): $277-80$

4 Liu H-K, Lee B J, Liu P-P (2007) Low cycle fatigue of single crystal silicon thin films. Sensors Actuators A 140:257-65

5 Muhlstein C L, Brown S B, Ritchie R O (2001) High-cycle fatigue of single-crystal silicon thin films. J. Microelectromech. Syst. 10:593-600

6 Pierron O N, Muhlstein C L (2006) The critical role of environment in fatigue damage accumulation in deep-reactive ion-etched single-crystal silicon structural films. J. Microelectromech. Syst. 15:111-9 
7 Ikehara T, Tsuchiya T (2008) High-cycle fatigue of micromachined single-crystal silicon measured using high-resolution patterned specimens. J Micromech Microeng 18: 075004.

8 Tsuchiya T, Tabata O, Sakata J, Taga Y (1998) Specimen size effect on tensile strength of surface-micromachined polycrystalline silicon thin films: $J$ Microelectromech Syst 7:106-13.

9 Tsuchiya T, Inoue A, Sakata J (2000) Tensile testing of insulating thin films; Humidity effect on tensile strength of $\mathrm{SiO}_{2}$ films. Sens Actuators 82:286-90

10 Nakao S, Ando T, Shikida M, Sato K (2006) Mechanical properties of a micron-sized SCS film in a high-temperature environment. J. Micromech. Microeng. $16: 715-20$

11 Nakao S, Ando T, Shikida M, Sato K (2008) Effect of temperature on fracture toughness in a single-crystal-silicon film and transition in its fracture mode. J. Micromech. Microeng. 18:015026

12 Ando T, Shikida M, Sato K (2001) Tensile-mode fatigue testing of silicon films as structural materials for MEMS. Sensors Actuators A 93:70-5 
13 Namazu T, Isono $\mathrm{Y}$ (2004) High-cycle fatigue damage evaluation for micro-nanoscale single crystal silicon under bending and tensile stressing. Tech. Dig. 17th Int. IEEE MEMS Conf. (Maastricht): 149-52

14 Muhlstein CL, Brown SB, Ritchie RO (2001) High-cycle fatigue and durability of polycrystalline silicon thin films in ambient air. Sens. Actuators A 94:177-88

15 Kahn H, Ballarini R, Bellante J, Heuer AH (2002) Fatigue failure in polysilicon not due to simple stress corrosion cracking. Science 298:1215-8

16 Tsuchiya T, Sakata J (2001) Tensile testing of thin films using electrostatic force grip. ASTM STP 1413: Mechanical Properties of Structural Films:214-28.

17 Goto H, Ikeda M, Sakata M, Imanaka K (1996) Development of Miniature Two-Dimensional Optical Scanner (2). Transaction of the Japan Society of Mechanical Engineers. 62:3202-9 (in Japanese).

18 Bagdahn J, Sharpe Jr. W N (2003) Fatigue of polycrystalline silicon under long-term cyclic loading. Sensors and Actuators A 103:9-15. 
Table 1:

\begin{tabular}{|c|c|}
\hline Maximum tensile force & $0.2 \mathrm{~N}$ \\
\hline Maximum stage displacement & $30 \mu \mathrm{m}$ \\
\hline Test frequency & $100 \mathrm{~Hz}$ \\
\hline Temperature & Room Temp. \\
\hline Humidity & $20-100 \%$ \\
\hline
\end{tabular}

Table 2:

\begin{tabular}{|c|c|c|c|c|c|c|}
\hline \multirow{2}{*}{} & \multicolumn{3}{|c|}{ Temperature $\left[{ }^{\circ} \mathrm{C}\right]$} & \multicolumn{3}{c|}{ Humidity [\%RH] } \\
\cline { 2 - 7 } & Average & Max. & Min. & Average & Max. & Min. \\
\hline Low Humidity & 25.7 & 27.0 & 24.7 & 26.9 & 29.2 & 25.3 \\
\hline Laboratory Air & 25.1 & 26.0 & 25.0 & 59.7 & 65.0 & 55.0 \\
\hline High Humidity & 25.8 & 26.9 & 24.7 & 86.9 & 89.3 & 85.0 \\
\hline
\end{tabular}

Figure 1:

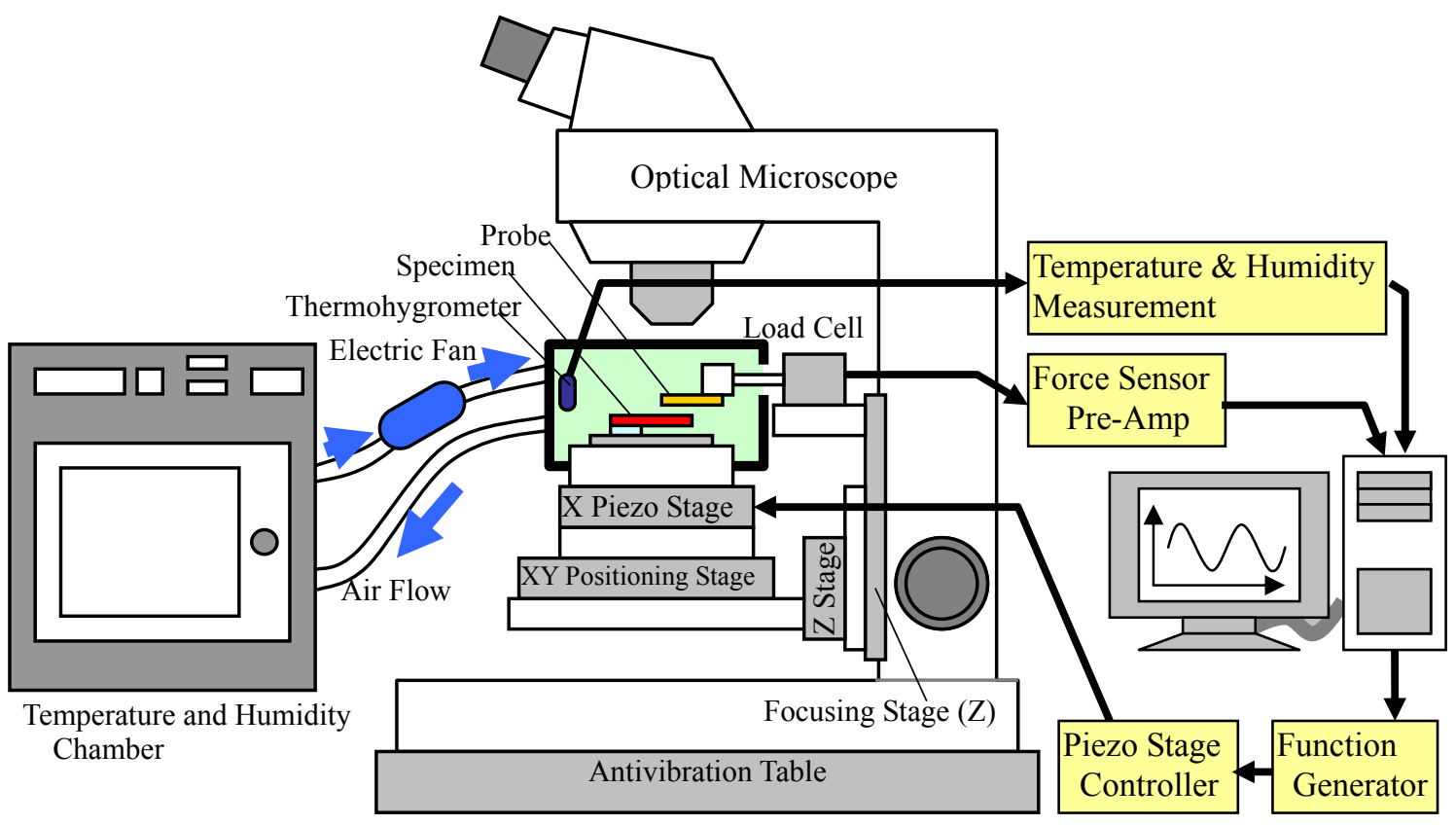


Figure 2:
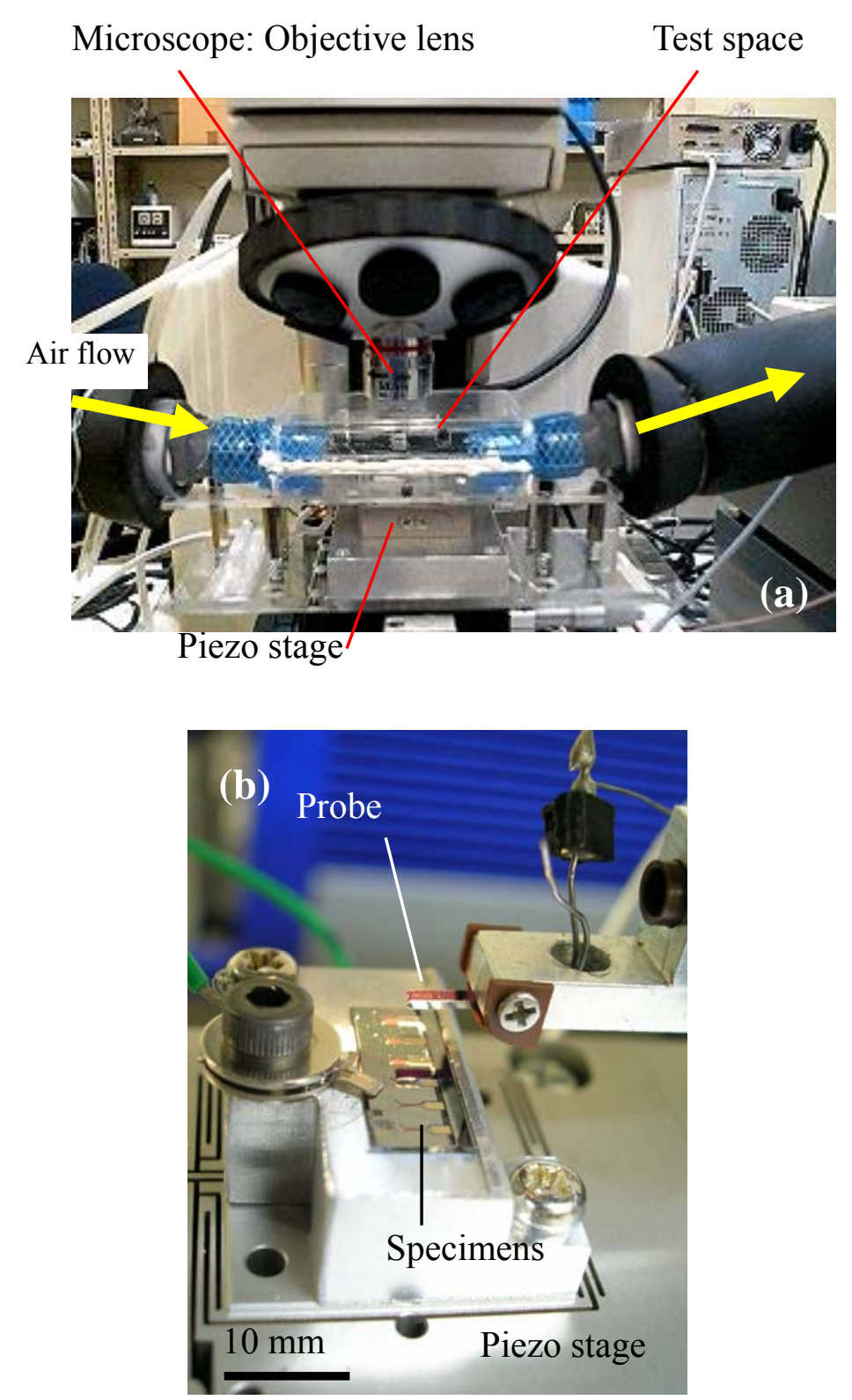
Figure 3:

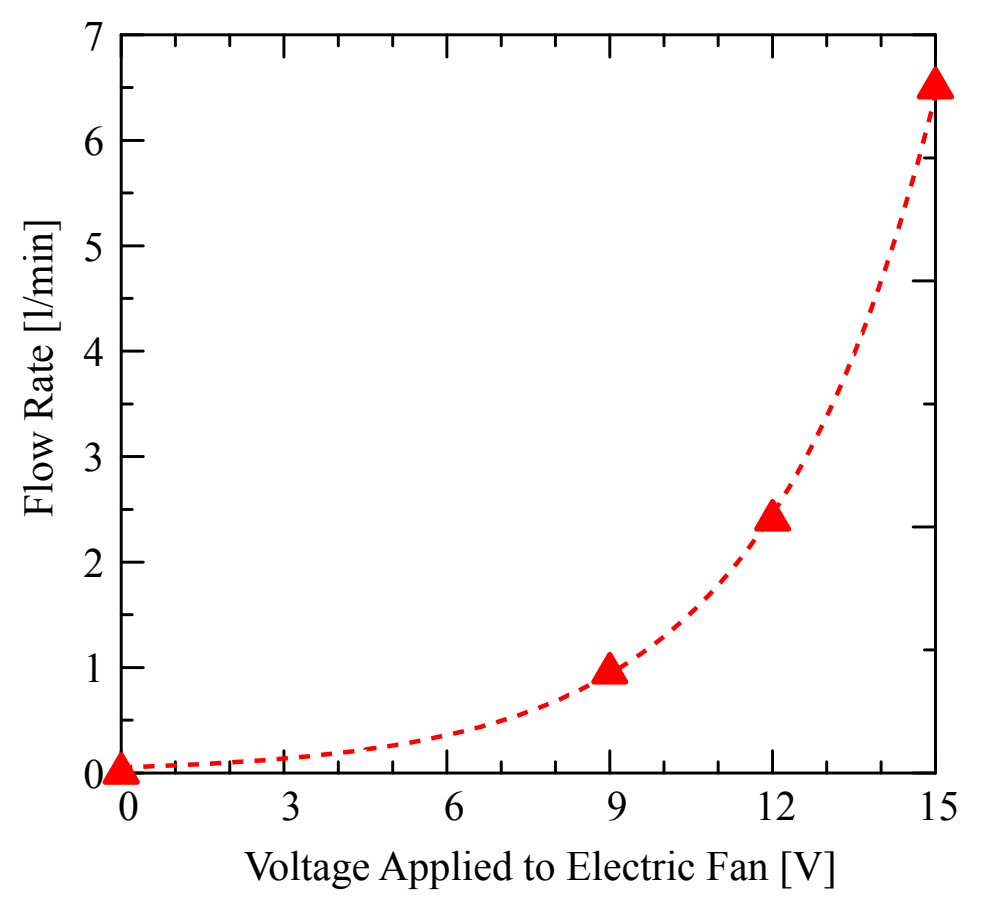

Figure 4:

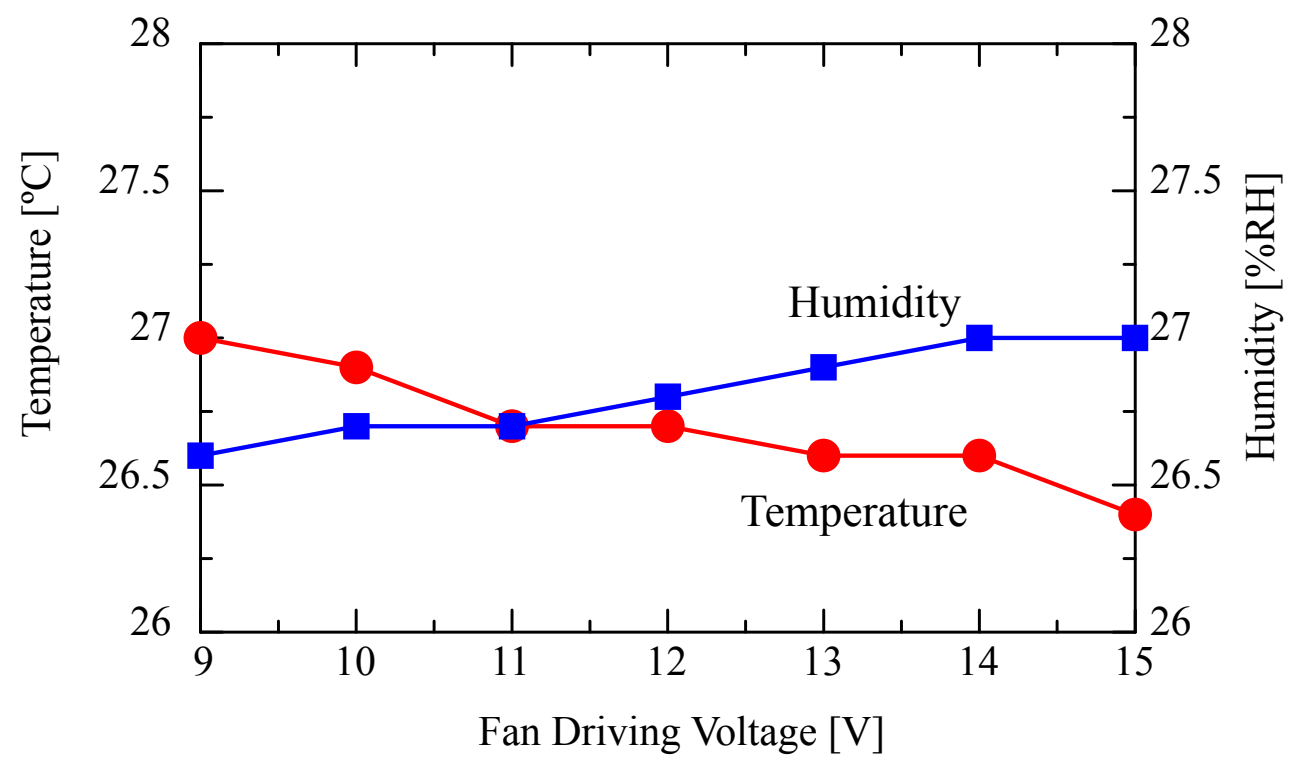


Figure 5:

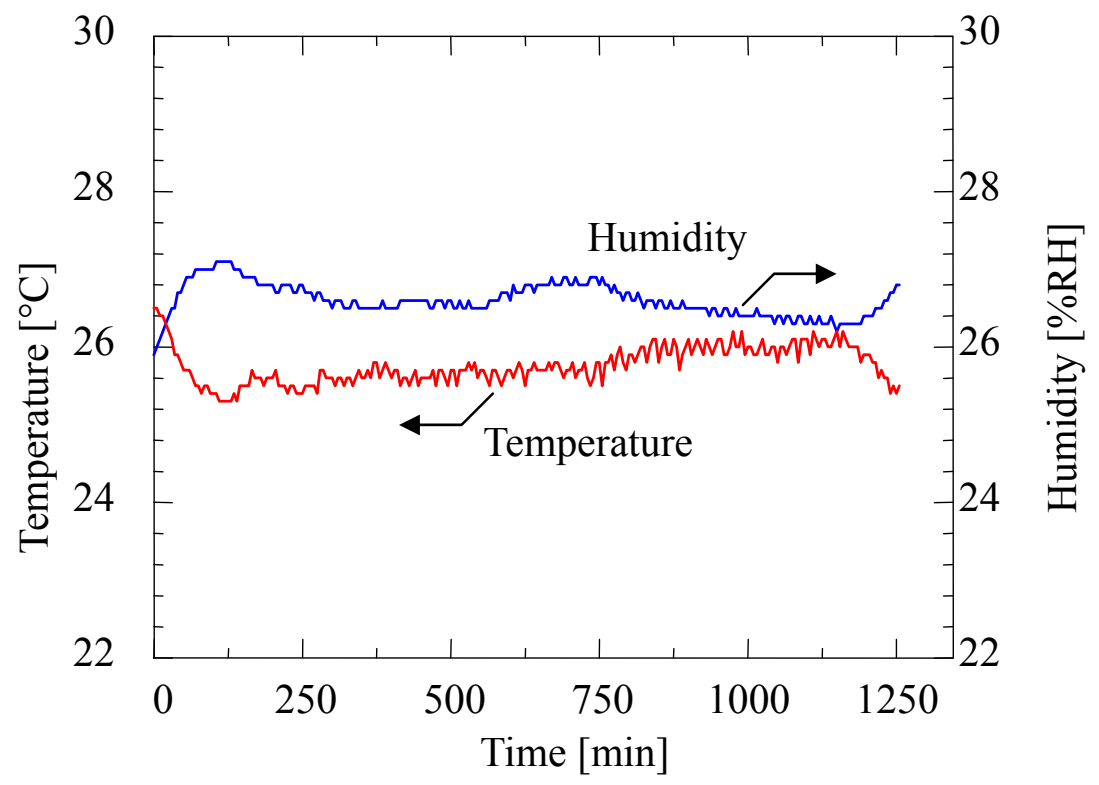

Figure 6:

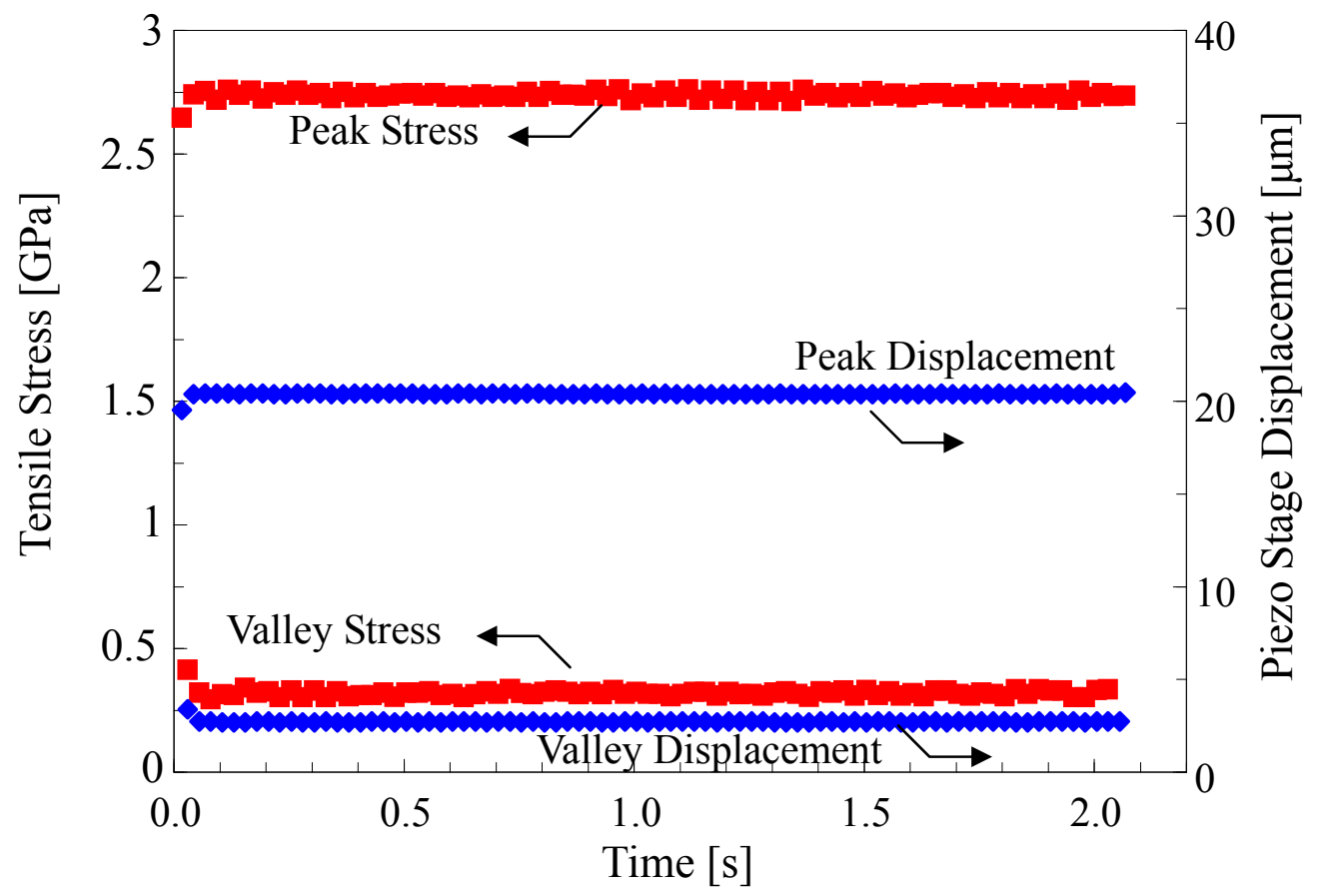


Figure 7:

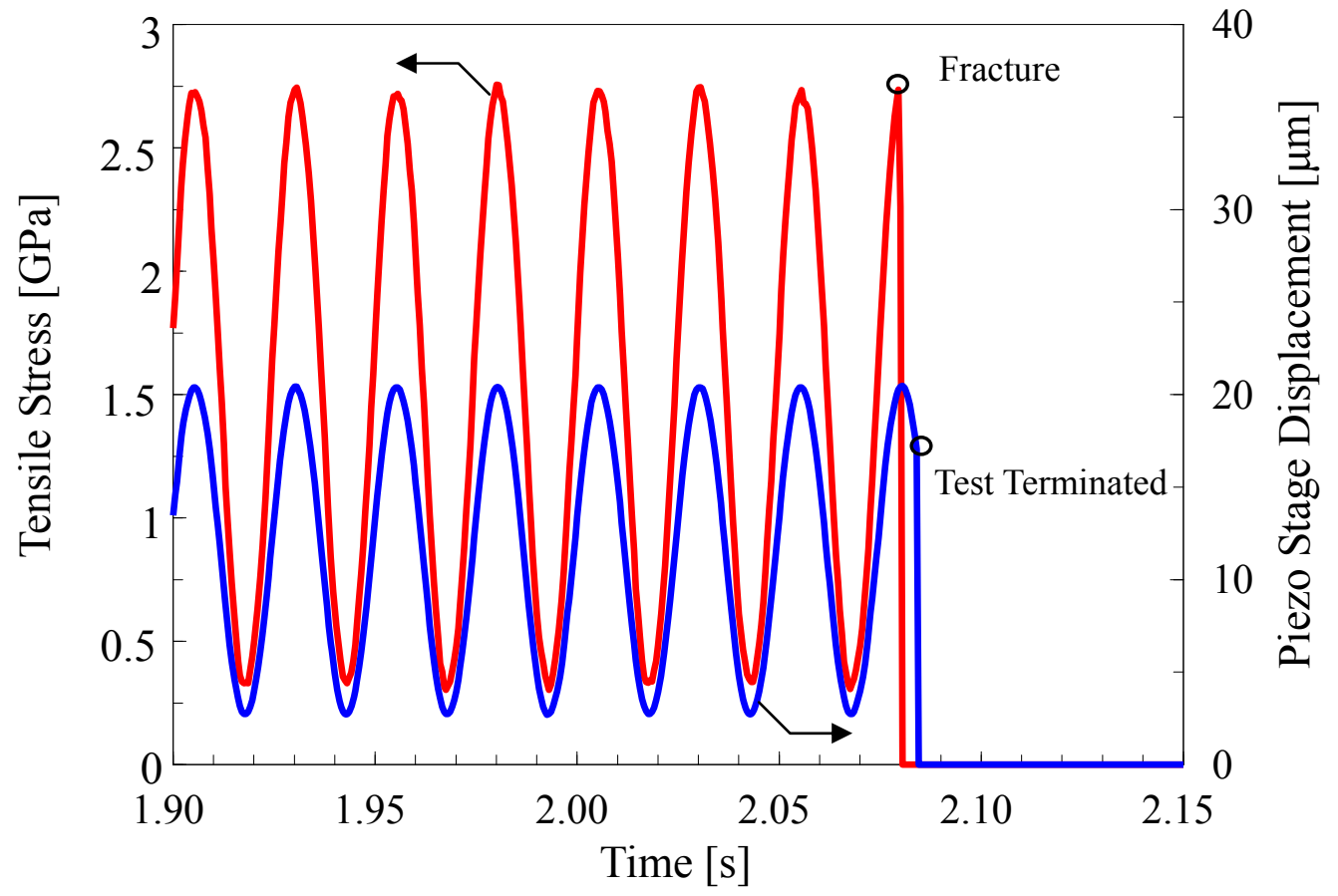

Figure 8:

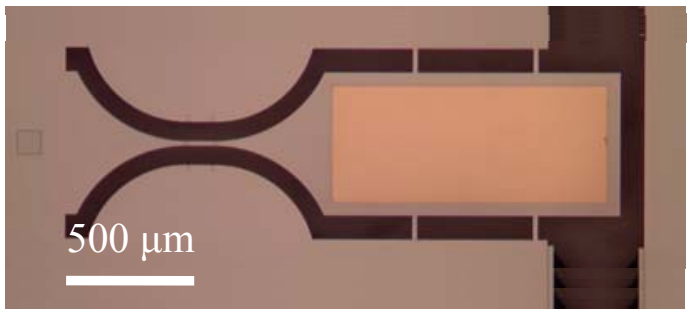

(a)

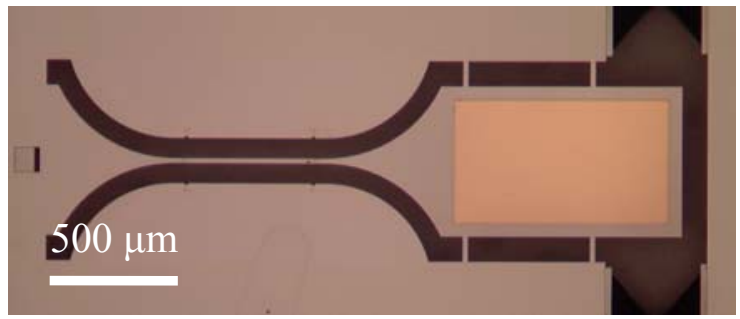

(b) 
Figure 9:

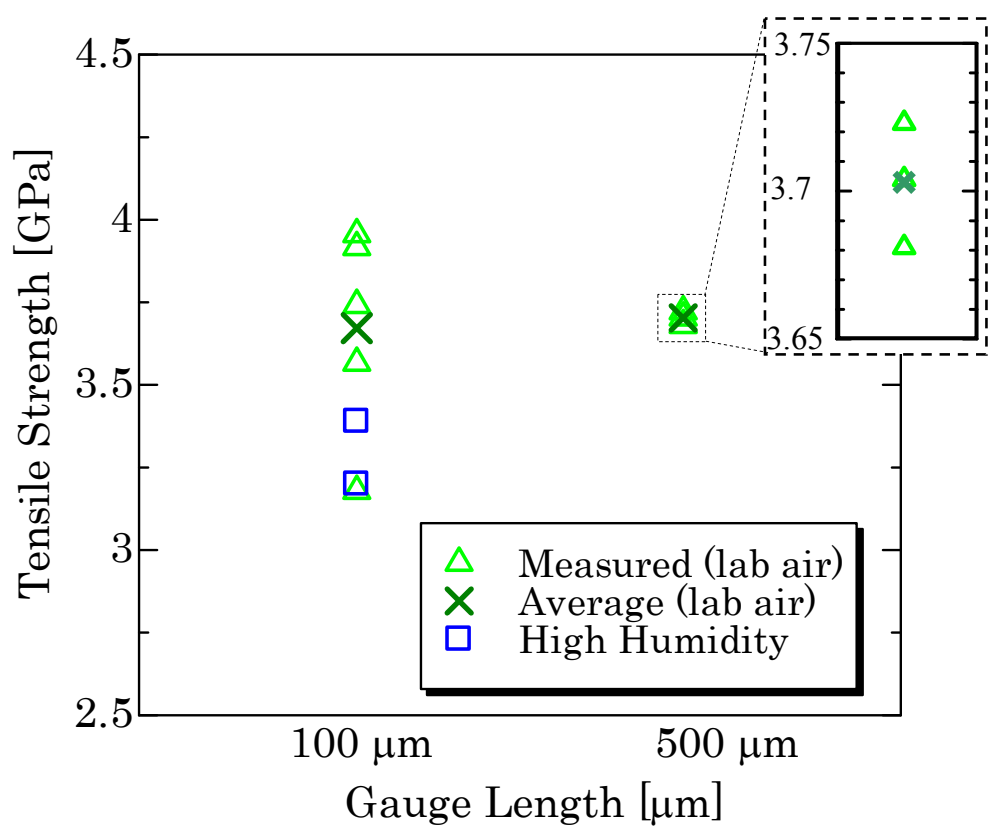

Figure 10:

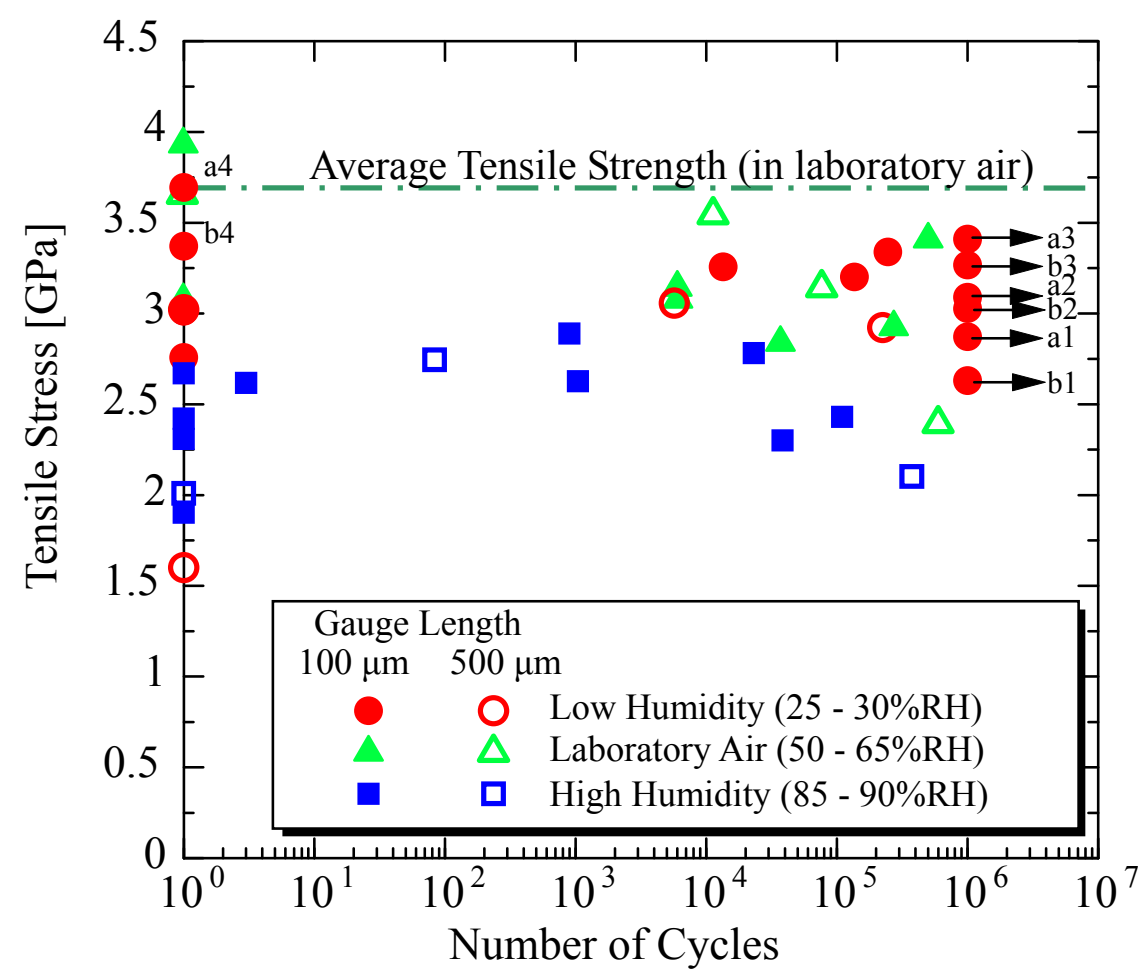

Figure 11: 

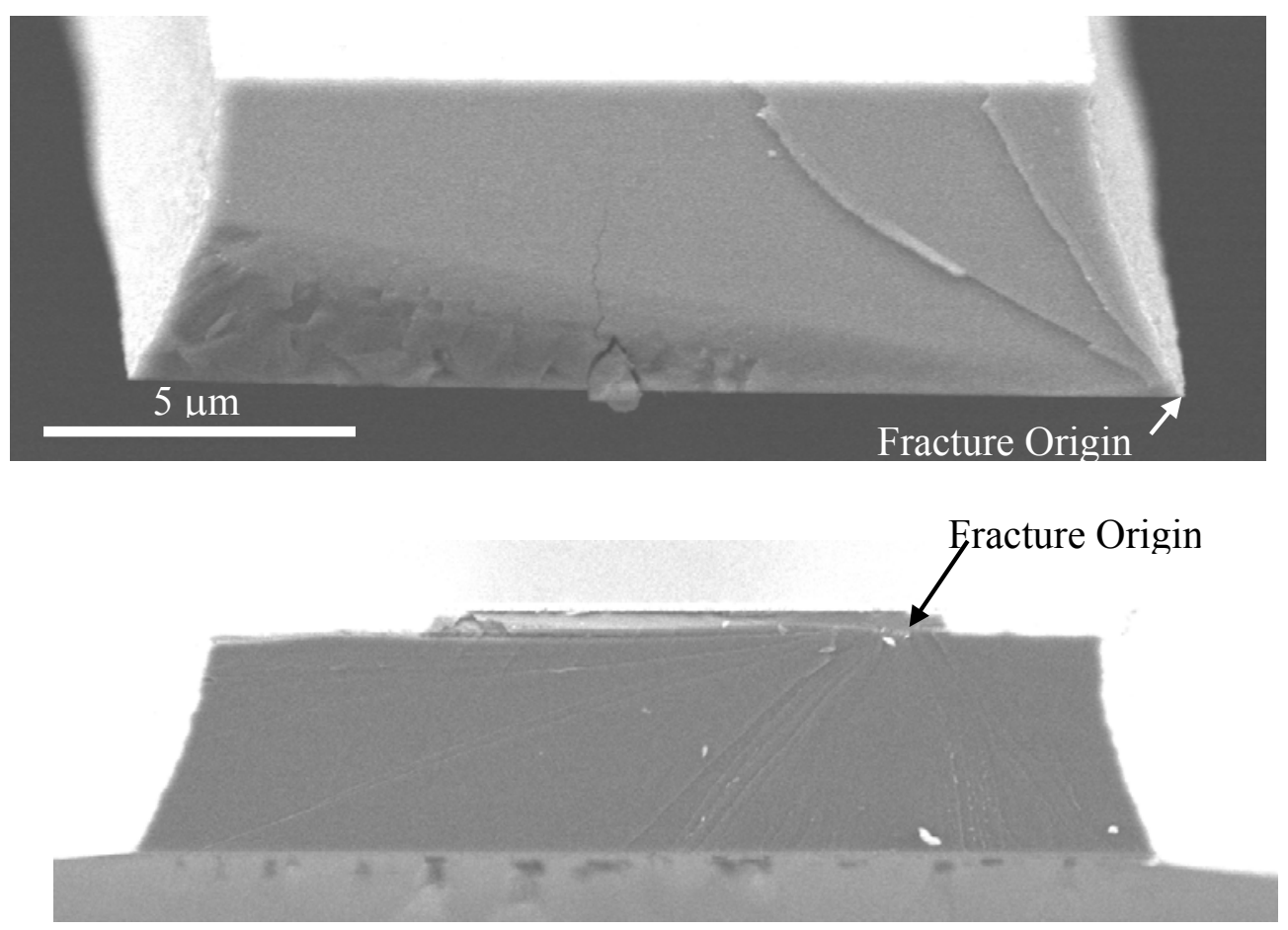

$5 \mu \mathrm{m}$ 